\title{
Modifikasi Jalur Pipa pada Keluaran Peralatan Media Penyaring Bertingkat dengan Pemasangan Penyaring Tipe $\mathrm{Y}$ pada PLTU Sebalang
}

\author{
Modification of Pipelines at The Output of Strategic Filtering Media \\ Equipment With Installation of Y-Type Filter at PLTU Sebalang
}

\author{
Muh Thohirin $^{*}$, Agus Apriyanto ${ }^{2}$ \\ 1,2Program Studi Teknik Sipil Universitas Sang Bumi Ruwa Jurai \\ Email :muhtohirin21@gmail.com ${ }^{1}$, agus.apriyanto89@gmail.com ${ }^{2}$
}

\begin{abstract}
Abstrak
Pengoptimalan kinerja media penyaring membran dalam meminimalisir garam mineral pada air laut dengan modifikasi jalur pipa pada keluaran peralatan media penuyaring bertingkat dengan pemasangan penyaring tipe Y pada PLTU Sebalang adalah suatu modifikasi pada media penyaring bertingkat (MGF) dengan tujuan agar pasir tidak lolos sampai ke media penyaring membran (SWRO), sehingga menyebabkan kinerja atau kemampuan maminimalisir garam mineral dari media penyaring membran (SWRO) menjadi turun. Modifikasi dilakukan dengan pemasangan spenyaring tipe $\mathrm{Y}$ pada jalur keluaran pipa peralatan media penyaring bertingkat (MGF) dengan tujuan media filter pasir tertahan pada media penyaring Y, sehingga tidak merusak membran dan mengembalikan kinerja membran. Pengambilan data dilakukan dengan percobaan sebelum dan sesudah modifikasi. Analisis data dilakukan dengan membandingkan jumlah pasir yang lolos terhadap kemampuan minimalisir media penyaring membran (SWRO). Didapatkan pasir yang lolos pada bulan Mei, Juni dan Juli 2020 adalah sebanyak 5,05 gram, 4,73 gram dan 4,75 gram dengan kemampuan salt rejction membran SWRO sebelum modifikasi masing masing 93,75\%, 93,66\% dan 95,94\%. Kemudian setelah dilakukan modifikasi didapatkan pasir yang lolos pada bulan Mei, Juni dan Juli 2020 adalah sebanyak 2,27 gram, 2,28 gram dan 2,33 gram dengan kemampuan salt rejection setelah modifikasi masing-masing $99,08 \%, 99,16 \%$ dan $99,10 \%$.
\end{abstract}

Kata kunci: Reverse Osmosis, Media Penyaring Bertingkat, Penyaring tipe Y Salt Rejection

\begin{abstract}
Optimizing the performance of the membrane filter media in minimizing mineral salts in seawater by modifying the pipeline at the output of the multilevel filter media equipment with the installation of a $Y$ type filter at the Sebalang PLTU is a modification of the multilevel filter media (MGF) with the aim that the sand does not pass to the filter media. membrane (SWRO), thus causing the performance or ability to minimize mineral salts from the membrane filter media (SWRO) to decrease. Modifications were made by installing a $Y$-type filter at the output line of the multilevel filter media equipment $(M G F)$ with the aim that the sand filter media was stuck on the $Y$ filter media, so as not to damage the membrane and restore membrane performance. Data were collected by experiment before and after modification. Data analysis was carried out by comparing the amount of sand that passed to the ability to minimize membrane filter media (SWRO). The sand that passed in May, June and July 2020 was 5.05 grams, 4.73 grams and 4.75 grams with the ability of SWRO membrane salt rejection before modification, respectively $93.75 \%, 93.66 \%$ and $95,94 \%$. Then after the modification, the sand that passed in May, June and July 2020 was 2.27 grams, 2.28 grams and 2.33 grams with salt rejection ability after modification of 99.08\%, 99.16\%, respectively. and $99.10 \%$.
\end{abstract}




\section{PENDAHULUAN}

PLTU Sebalang adalah salah satu unit pembangkit yang berada di bawah lingkup PT. PLN (persero) Pembangkitan Sumatera Bagian Selatan Sektor Pembangkitan Sebalang. PLTU Sebalang merupakan PLTU dengan boiler tipe Circulating Fluidized Bed (CFB) yang termasuk kedalam Fast Track Program (FTP) 10.000 MW tahap 1 yang di desain oleh PT. JINAN (Perusahaan asal Tiongkok) dan mulai dioperasikan oleh PT. PLN (Persero) Sektor Pembangkitan Sebalang pada tahun 2016.

Boiler PLTU tipe CFB menggunakan bed material berupa limestone (kapur), inert bed (pasir kuarsa) yang digunakan sebagai media transfer panas di dalam furnace (ruang bakar) dan air laut sebagai bahan dasar yang diolah untuk menjadi air demin yang akan menjadi uap untuk memutar turbin [1]

Pengoperasian PLTU Sebalang menggunakan air demin sebagai bahan penggerak turbin, dimana air demin tersebut dipanaskan sampai menjadi uap kering yang bertekanan. Air demin yang dipakai berasal dari air laut yang diolah menjadi air murni pada suatu sistem yaitu reverse osmosis (RO), yaitu dengan penghilangan kadar garam (Salitnitas) menggunakan membrane vessel [2].

Dalam proses pengolahan nya, air laut disaring/dipisahkan kotoran atau impurity nya menggunakan peralatan filtrasi yaitu media penyaring bertingkat (MGF). Media penyaring bertingkat (MGF) merupakan suatu peralatan filtrasi yang memiliki tingkatan bed material seperti batu-batuan (Pebbles), batu kerikil, pasir halus (Fine Sand). Permasalahan yang dialami pada sistes reverse osmosis PLTU sebalang ini yaitu lolos atau keluarnya bed material pasir halus (Fine Sand) pada peralatan media penyaring bertingkat (MGF) yang pada ujungnya menimbulkan masalah rusaknya ukuran pori membran sehingga turun nya kinerja atau kemampuan meminimalisir garam mineral pada media penyaring membran (SWRO) dan turun nya kualitas air yang dihasilkan menjadi kurang baik. Dikarenakan sering lolos nya pasir padasistem media penyaring bertingkat (MGF) dengan kondisi yang harus selalu beroperasi maka perlu dilakukan modifikasi yang tepat dan efektif pada peralatan media penyaring bertingkat (MGF) yaitu dengan memodifikasi jalur pipa keluaran media penyaring bertingkat (MGF) dengan memasang media penyaring tipe $\mathrm{Y}$ yang dapat mencegah lolosnya pasir pada media penyaring bertingkat (MGF) yang dapat menurunkan kinerja dari media penyaring membran (SWRO). [1].

Penelitian ini dirasa penting untuk dilakukan dalam meminimalisir lolosnya pasir pada peralatan media penyaring bertingkat (MGF) serta mengoptimalkan kemampuan meminimalisir garam mineral pada media penyaring membrane (SWRO).

\section{Sistem Pengolahan Air PLTU Sebalang}

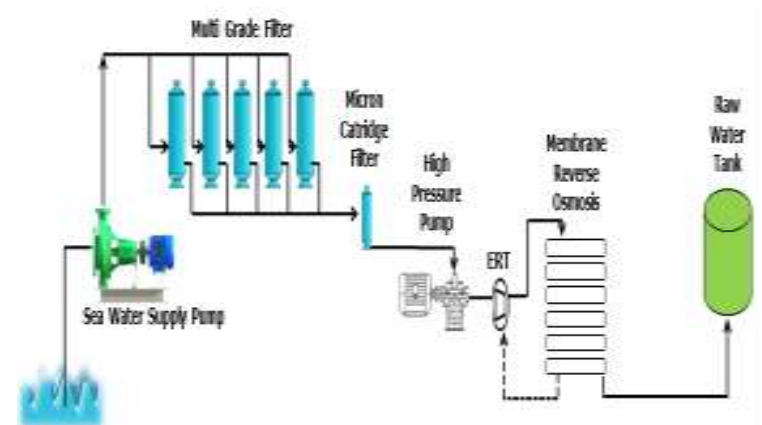

Gambar 1. Sistem Pengolahan Air di PLTU Sebalang

Proses pengolahan air pada PLTU Sebalang adalah seperti Gambar 1. di atas, air laut sebagai bahan baku diolah menjadi raw water hingga menghasilkan air demin pada unit pengolahan air melalui beberapa proses sebagaimana berikut:

\section{1) Proses Pre - Treatment}

Proses ini merupakan proses awal, dimana air laut diinjeksi bahan kimia 
chlorine dengan tujuan air laut yang akan menjadi umpan tidak memiliki kontaminasi mikroorganisme, sehingga tidak membentuk biofilm dan mengganggu efisiensi membran. Air laut sebagai umpan yang memiliki conductivity antara 50.000 uS/cm sampai $52.000 \mathrm{uS} / \mathrm{cm}$ di pompa dengan menggunakan sea water supply pump (SWP)

\section{2) Proses RO (Reverse Osmosis)}

Salah satu teknologi yang dapat diterapkan untuk mengolah air asin atau payau menjadi air tawar adalah dengan sistem Reverse Osmosis (RO). Pengolahan dengan menggunakan Reverse Osmosis merupakan pengolahan proses fisika yang dilakukan dengan memberikan tekanan untuk menahan semua ion dan melepaskan air murni dan membuang air kotor berupa mineral-mineral garam yang tertahan. Keuntungan menggunakan proses ini ialah zat organik, bakteri, pirogen serta koloid dapat dihilangkan karena adanya struktur pori Reverse Osmosis yang mampu menahan dan berfungsi sebagai penyaring zat-zat tersebut [3]

\section{3) Klasifikasi Membran}

Membran didefinisikan sebagai suatu media berpori, berbentuk film tipis, bersifat semipermiabel yang berfungsi untuk memisahkan partikel dengan ukuran molekuler (spesi) dalam suatu sistem larutan. Spesi yang memiliki ukuran yang lebih besar dari pori membran akan tertahan sedangkan spesi dengan ukuran yang lebih kecil dari pori membran akan lolos menembus pori membran [4]. Proses pemisahan dengan membran dapat terjadi karena adanya perbedaan ukuran pori, bentuk, serta struktur kimianya. Membran demikian biasa disebut sebagai membran semipermiable, artinya dapat menahan spesi tertentu, tetapi dapat melewatkan spesi yang lainnya. Fasa campuran yang akan dipisahkan disebut umpan (feed), hasil pemisahan disebut sebagai permeat [5]

\section{4) Prinsip Kerja Membran}

Proses Pemisahan dengan menggunakan media membran dapat terjadi karena membran mempunyai sifat selektifitas yaitu kemampuan untuk memisahkan suatu partikel dari campurannya. Hal ini dikarenakan partikel memiliki ukuran lebih besar dari pori membran. Untuk lebih jelasnya mengenai proses pemisahan dengan menggunakan membran dapat dilihat pada Gambar 2. berikut :

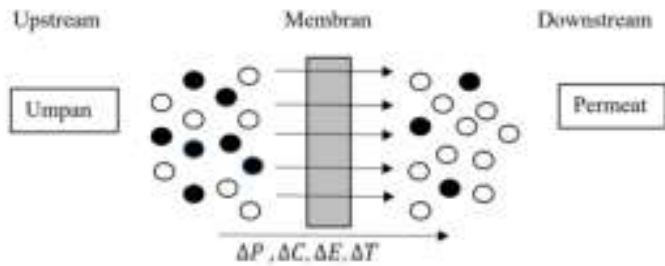

Gambar 2. Proses pemisahan dengan membran [6]

Pengoptimalan kemampuan membran dalam meminimalisir garam mineral pada air laut dengan modifikasi jalur pipa pada keluaran peralatan penyaring tipe saringan bertingkat dengan pemasangan penyaring tipe $\mathrm{Y}$ ini adalah dengan melakukan percobaan sebelum dan sesudah dilakukan modifikasi.

\section{Media Penyaring Membran (SWRO)}

Air laut sebelum memasuki membran terlebih dahulu di injeksi dengan bahan kimia berupa Sodium Metha Bisulphite (SMBS) dengan tujuan agar kandungan chlorine tidak berlebihan sebelum memasuki membran, injeksi ini dilakukan agar meminimalisir penyebabkan membran menjadi getas. Selanjutnya air laut juga diinjeksi dengan bahan kimia berupa Anti Scalant, injeksi bahan kimia ini bertujuan agar melunakkan air laut yang akan dijadikan umpan untuk masuk ke membran. Kemudian selanjutnya diinjeksi dengan $\mathrm{HCl}$ dengan tujuan agar $\mathrm{pH}$ yang masuk ke membran sesuai dengan batas range yang telah ditentukan. Air laut yang telah 
memiliki kualitas yang dipersyaratkan kemudian melewati vessel yang berisi suatu media filter berupa catridge yang bernama Micron Catridge Filter (MCF) dengan tujuan agar suspensi terlarut dan unsur $\mathrm{Fe}$ didalam air dapat tertahan di catridge, sehingga air laut memiliki kualitas yang bagus sebelum memasuki membran reverse osmosis [7].

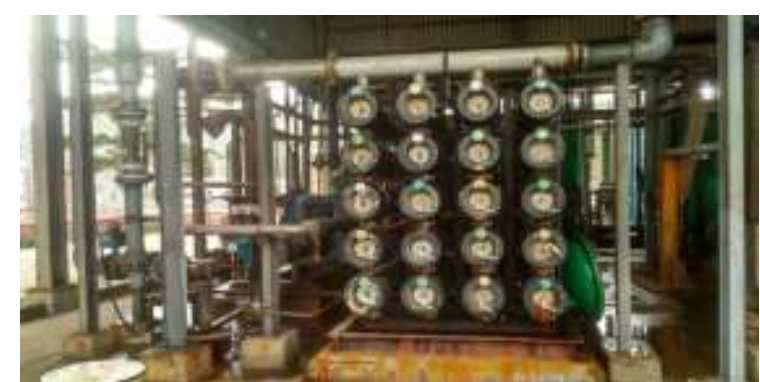

Gambar 3. Unit Media Penyaring Membran (SWRO) di PLTU Sebalang

\section{Media Penyaring Membran (BWRO)}

Prodak atau permeate dari media penyaring membran (SWRO) adalah feed media penyaring membran (BWRO) yang ditampung didalam brackish tank, kemudian feed media penyaring membran (BWRO) ini dipompa dengan high pressure pump media penyaring membran (BWRO) pada tekanan 10 bar untuk diolah pada media penyaring membran (BWRO) untuk mendapatkan nilai konduktivitas hingga $\leq 10 \mu \mathrm{S} / \mathrm{cm}$.

Prodak dari BWRO kemudian diolah kembali pada suatu unit vessel degasifier yang berfungsi untuk menghilangkan gas gas terlarut didalam air yang bisa menyebabkan korosi didalam air. Keluaran dari degasifier ini disebut dengan raw water.

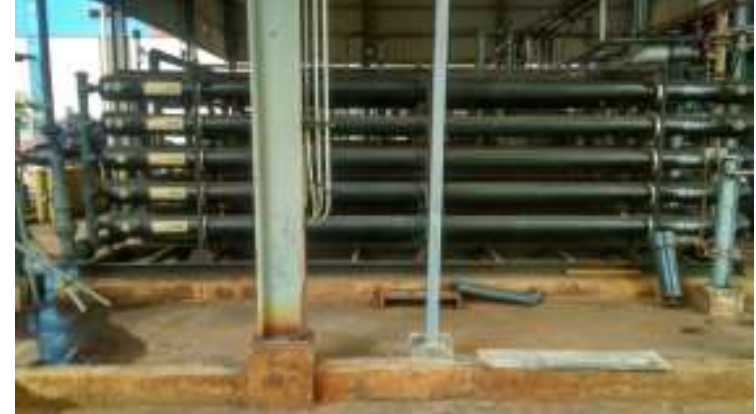

Gambar 4. Unit Media Penyaring Membran (BWRO) di PLTU Sebalang

\section{METODE PENELITIAN}

Penelitian ini dilakukan di PLTU Sebalang Kecamatan Katibung Lampung Selatan. Pengumpulan data dilakukan dengan cara mengabil data aktual pada saat sebelum dilakukan nya modifikasi dan setelah dilakukannya modifikasi. Data operasi didapatkan dari DCS (Distributed Control System), data desain yang didapat dari manual book pada arsip bagian Balance of Plant (BOP).

Setelah melakukan percobaan pada kondisi sebelum dan sesudah modifikasi, selanjutnya dilakukan pengolahan data untuk dilakukan analisa data dan di bandingkan pada saat kondisi sebelum dan sesudah modifikasi. Berikut format perhitungan nya adalah sebagai berikut :

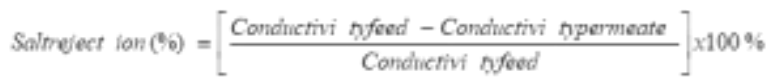

Keterangan :

E.C Feed : Kondaktifitas masuk media penyaring membrane (SWRO)

E.C Permeate : Kondaktifitas keluaran media penyaring membran (SWRO)

Tahapan penelitian dapat dilihat pada bagan alir berikut. 


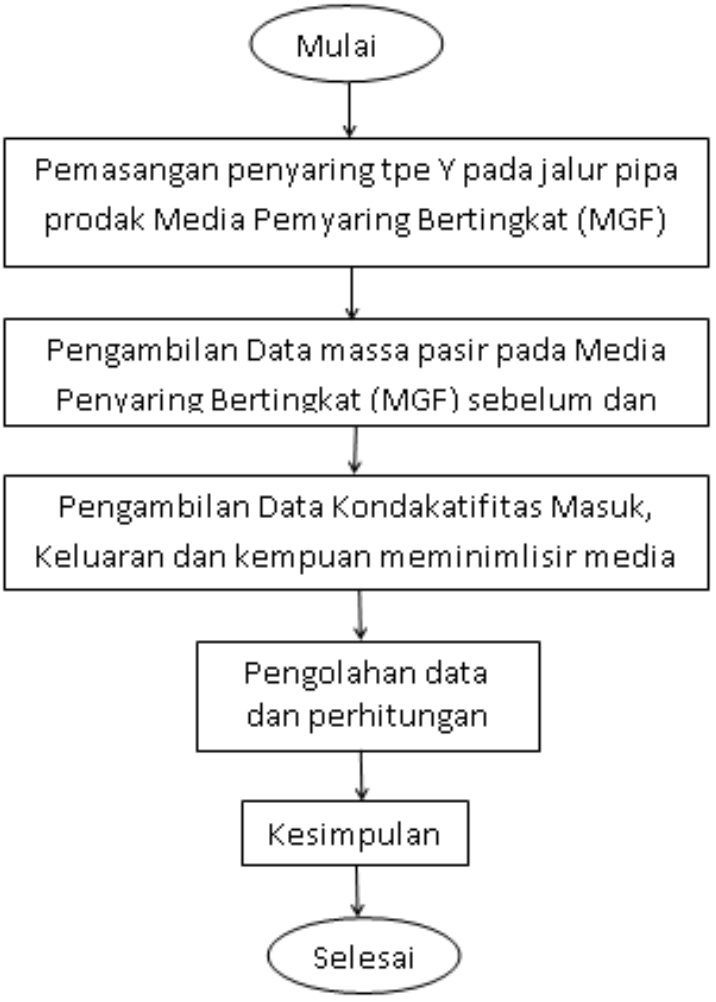

Gambar 5. Diagram Alir Penelitian

\section{HASIL DAN PEMBAHASAN}

\section{Pemasangan Penyaringan Tipe $Y$}

Penyaring tipe $\mathrm{Y}$ merupakan terobosan untuk mencegah lolosnya pasir dari peralatan media penyaring bertingkat (MGF) yang masuk ke sistem media penyaring membran (SWRO) yang di nilai mudah pemasangannya dan efisien. Pemasangan penyaring tipe $\mathrm{Y}$ pada peralatan media penyaring bertingkatt (MGF) ini tidak mengganggu kinerja produksi air untuk kebutuhan unit yang dituntut harus beroperasi. Visualisasi sesudah pemasangan saringan tipe $\mathrm{Y}$ dapat dilihat pada Gambar 6 yang merupakan dokumentasi saringan tipe $\mathrm{Y}$ yang digunakan pada peralatan media penyaring bertingkat (MGF).

Saringan tipe $\mathrm{Y}$ pada peralatan media penyaring bertingkat (MGF) menggunakan model transparan untuk monitoring impurity atau pasir media penyaring bertingkat (MGF) yang lolos.

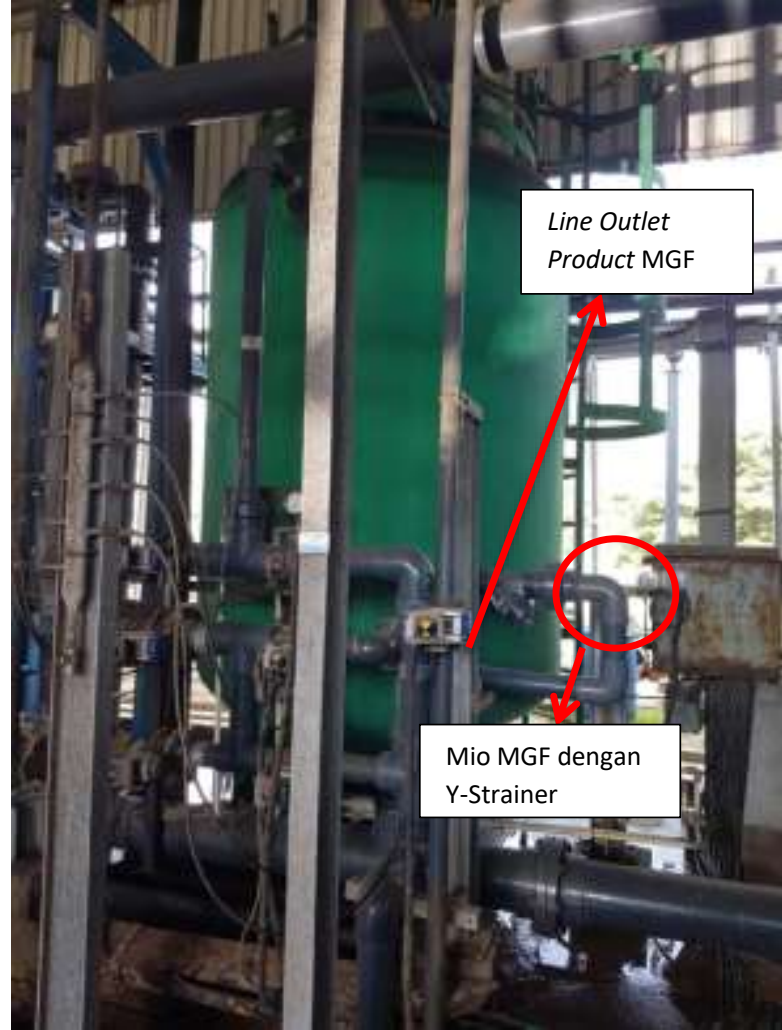

Gambar 6. Pemasangan Penyaring Tipe Y di PLTU Sebalang

\section{Modifikasi Bulan Mei 2020}

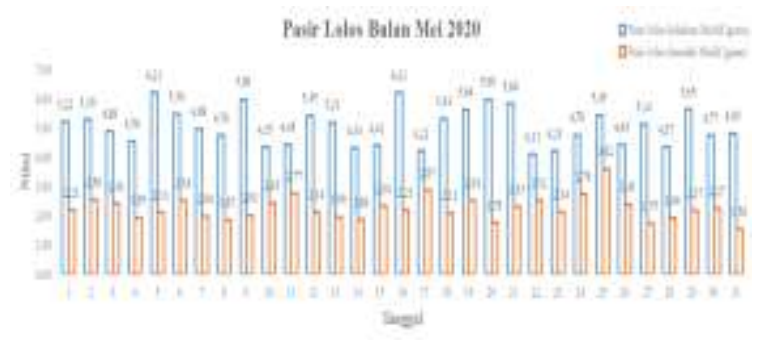

Gambar 7. Massa pasir lolos sebelum dan sesudah modifikasi pada bulan Mei 2020

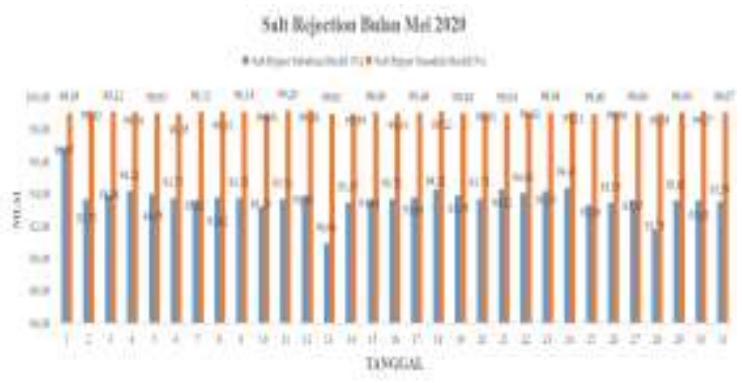

Gambar 8. Salt Rejection sebelum dan sesudah modifikasi pada bulan Mei 2020 
Berdasarkan Gambar 7 dan Gambar 8 di atas dapat dianalisa bahwa pada bulan Mei 2020 dengan kondisi sebelum modifikasi didapatkan rata - rata pasir yang keluar atau lolos adalah sebanyak 5,05 gram, namun setelah dilakukan modifikasi dengan pemasangan saringan tipe $\mathrm{Y}$ didapatkan hasil pasir yang lolos rata - rata nya adalah 2,27 gram.

Berdasarkan Gambar 7 dan Gambar 8 di atas juga dapat dianalisa bahwa pada bulan Mei 2020 dengan kondisi sebelum modifikas didapatkan rata - rata kemampuan minimalisir garam mineral pada media penyaring membran (SWRO) adalah sebesar $93,75 \%$ nilai ini jauh sekali bila dibandingkan dengan kemampuan minimalisir garam rata - rata sesudah dilakukan modifikasi yaitu $99,08 \%$.

\section{Modifikasi Bulan Juni 2020}

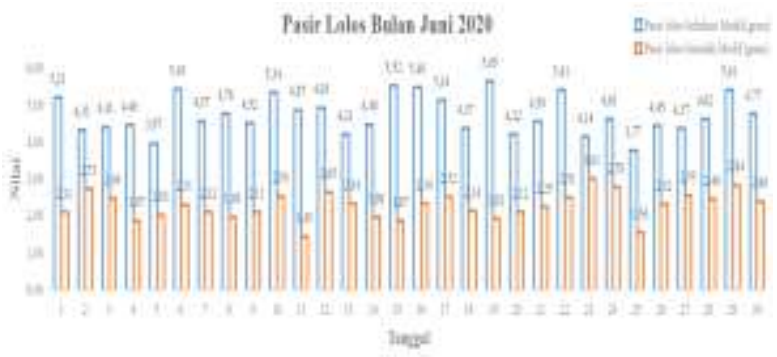

Gambar 9. Massa pasir lolos sebelum dan sesudah modifikasi pada bulan Juni 2020

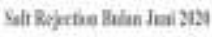
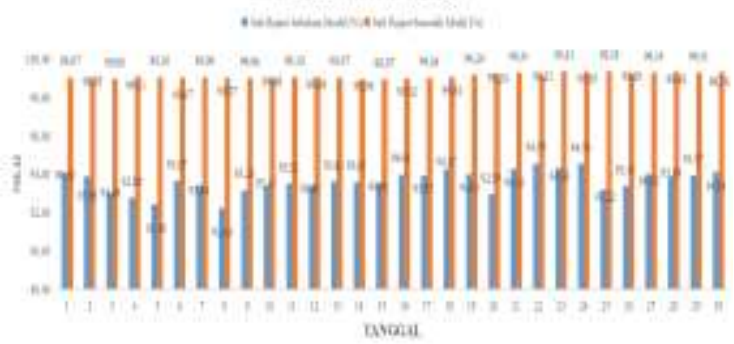

Gambar 10. Salt Rejection sebelum dan sesudah modifikasi pada bulan Juni 2020

Berdasarkan Gambar 9 dan Gambar 10 diatas dapat dianalisa bahwa pada bulan Juni 2020 dengan kondisi sebelum modifikasi didapatkan rata - rata pasir yang keluar atau lolos adalah sebanyak 4,73 gram, namun setelah dilakukan modifikasi dengan pemasangan saringan tipe $Y$ didapatkan hasil pasir yang lolos rata - rata nya adalah 2,28 gram.

Berdasarkan Gambar 9 dan Gambar 10 di atas juga dapat dianalisa bahwa pada bulan Juni 2020 dengan kondisi sebelum modifikasi didapatkan rata - rata kemampuan minimalisir garam mineral pada media penyaring membran (SWRO) adalah sebesar $93,66 \%$. Nilai ini jauh sekali bila dibandingkan dengan kemampuan minimalisir garam rata - rata sesudah dilakukan modifikasi yaitu 99,16\% .

\section{Modifikasi Bulan Juli 2020}

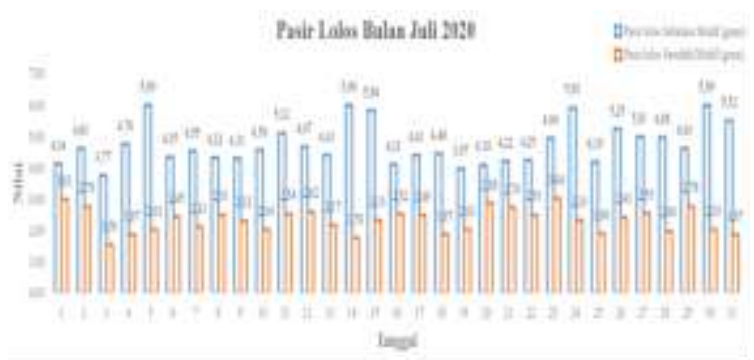

Gambar 11. Massa pasir lolos sebelum dan sesudah modifikasi pada bulan Juli 2020

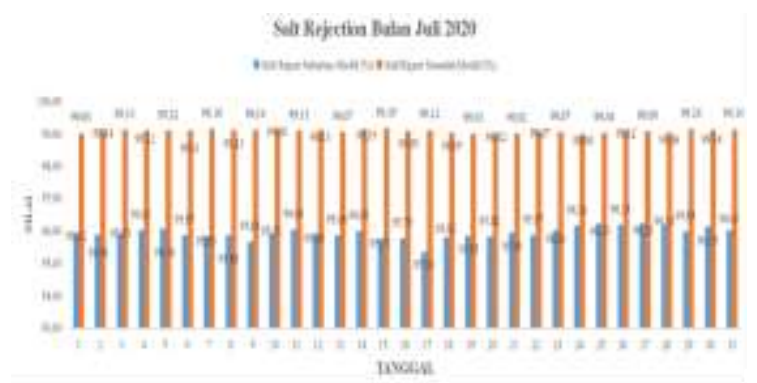

Gambar 12. Salt Rejection sebelum dan sesudah modifikasi pada bulan Juli 2020

Berdasarkan Gambar 11 dan Gambar 12 di atas dapat dianalisa bahwa pada bulan Juni 2020 dengan kondisi sebelum modifikasi didapatkan rata - rata pasir yang keluar atau lolos adalah sebanyak 4,75 gram, namun setelah dilakukan modifikasi dengan pemasangan saringan tipe $Y$ didapatkan hasil pasir yang lolos rata - rata nya adalah 2,33 gram. Turun nya pasir yang lolos pada saat sesudah modifikasi disebabkan karena pasir yang keluar 
tertahan pada penyaring tipe $\mathrm{Y}$, dimana pasir dengan ukuran 5 mesh tertahan pada penyaring tipe $\mathrm{Y}$ yang berukuran 20 mesh, sehingga menyebabkan jumlah pasir yang lolos menjadi sedikit dan berdampak pada naiknya kemampuan minimalisir garam pada membran SWRO

Berdasarkan Gambar 11 dan Gambar

12 di atas juga dapat dianalisa bahwa pada bulan Juni 2020 dengan kondisi sebelum modifikas didapatkan rata - rata kemampuan minimalisir garam mineral pada media penyaring membran (SWRO) adalah sebesar 95,94\%. Nilai ini jauh sekali bila dibandingkan dengan kemampuan minimalisir garam rata - rata sesudah dilakukan modifikasi yaitu $99,10 \%$. Naiknya kemampuan minimalisir garam tersebut karena efek dari berkurang nya pasir yang lolos sampai ke membran SWRO, sehingga menyebabkan pori pori pada membran SWRO menjadi tidak tersumbat karena pasir dan proses penyaringan berjalan dengan baik.

Berdasarkan kejadian di atas yaitu sebelum dilakukan modifikasi dan setelah dilakukan modifikasi dapat disimpulkan bahwa dengan jumlah pasir yang lebih sedikit dapat menyebabkan kerusakan pada pori pori membran menjadi lebih di minamalisir, sehingga proses semipermeable pada membran membaik dan menyebabkan salt rejection membran meningkat. Hal ini selaras dengan terori bahwa pemisahan dengan membran dapat terjadi karena adanya perbedaan ukuran pori, bentuk, serta struktur kimianya. Membran demikian biasa disebut sebagai membran semipermiable, artinya dapat menahan spesi tertentu, tetapi dapat melewatkan spesi yang lainnya. Fasa campuran yang akan dipisahkan disebut umpan (feed), hasil pemisahan disebut sebagai permeat [5].

\section{Analisa Sebelum dan Sesudah Modifikasi}

Tabel 1. Evaluasi data sebelum dan sesudah modifikasi bulan Mei, Juni dan Juli 2020

\begin{tabular}{|c|c|c|c|c|c|c|}
\hline \multirow{2}{*}{ Kondisi } & \multicolumn{2}{|c|}{ Mei 2020 } & \multicolumn{2}{c|}{ Juni 2020 } & \multicolumn{2}{c|}{ Juli 2020 } \\
\cline { 2 - 7 } & $\begin{array}{c}\text { Pasir } \\
\text { yang } \\
\text { lolos }\end{array}$ & $\begin{array}{c}\text { Salt } \\
\text { Rejection }\end{array}$ & $\begin{array}{c}\text { Pasir } \\
\text { yang } \\
\text { lolos }\end{array}$ & $\begin{array}{c}\text { Salt } \\
\text { Rejection }\end{array}$ & $\begin{array}{c}\text { Pasir } \\
\text { yang } \\
\text { lolos }\end{array}$ & $\begin{array}{c}\text { Salt } \\
\text { Rejection }\end{array}$ \\
\hline $\begin{array}{c}\text { Sebelum } \\
\text { Modifikasi }\end{array}$ & 5,05 & 93,75 & 4,73 & 93,66 & 4,75 & 95,94 \\
\hline $\begin{array}{c}\text { Sesuda } \\
\text { Modifikasi }\end{array}$ & 2,27 & 99,08 & 2,28 & 99,16 & 2,33 & 99,10 \\
\hline
\end{tabular}

Berdasarkan Tabel 1. di atas dapat di analisa bahwa dengan dilakukannya modifikasi pada line produk multi grade filter (MGF) sangat berpengaruh baik pada nilai pasir yang lolos setelah dilakukan modifikasi dengan $y$-strainer, dimana jumlah pasir yang lolos berkurang dan menyebabkan kinerja membran sea water reverse osmosis (SWRO) menjadi meningkat.

\section{KESIMPULAN}

Berdasarkan pembahasan dan analisa di atas, dapat ditarik kesimpulan sebagai berikut :

1. Dengan modifikasi saringan tipe $Y$ terjadi pengurangan jumlah pasir yang lolos pada peralatan media penyaring bertingkat (MGF), dimana pada bulan Mei 2020 sebelum modifikasi rata rata pasir yang lolos adalah sebesar 5,05 gram menjadi turun menjadi 2,27 setelah modifikasi dengan kemampuan minimalisir garam naik, dari $93,75 \%$ menjadi $99,08 \%$

2. Dengan modifikasi saringan tipe $Y$ terjadi pengurangan jumlah pasir yang lolos pada peralatan media penyaring bertingkat (MGF), dimana pada bulan Juni 2020 sebelum modifikasi rata rata pasir yang lolos adalah sebesar 4,73 gram menjadi turun menjadi 2,28 setelah modifikasi dengan kemampuan minimalisir garam naik, dari 93,66\% menjadi $99,16 \%$

3. Dengan modifikasi saringan tipe $Y$ terjadi pengurangan jumlah pasir yang 
lolos pada peralatan media penyaring bertingkat (MGF), dimana pada bulan Juli 2020 sebelum modifikasi rata rata pasir yang lolos adalah sebesar 4,75 gram menjadi turun menjadi 2,33 setelah modifikasi dengan kemampuan minimalisir garam naik, dari 95,94\% menjadi $99,10 \%$

\section{DAFTAR PUSTAKA}

[1] P. Manurung, "Studi Pembangkit Listrik Tenaga Uap dengan Menggunakan Bahan Bakar Biomassa (Aplikasi PT. Growth Asia)," Repos. Univ. HKBP Nommensen, 2016.

[2] I. G. depertemen teknik kimia I. Wenten, "Teknologi Membran Dalam Pengolahan Air Dan Limbah Industri," vol. lim, no. January 2004, p. 283, 2014.

[3] I. Kyrychuk, Y. Zmievskii, and V. Myronchuk, "Treatment of dairy effluent model nanofiltration and reverse osmosis solutions by," Process. Equip. Food Prod., vol. 3, no. 2, pp. 280-287, 2014.

[4] P. T. P. Aryanti, S. R. Joscarita, A. K. Wardani, S. Subagjo, D. Ariono, and I. G. Wenten, "The influence of PEG400 and acetone on polysulfone membrane morphology and fouling behaviour," J. Eng. Technol. Sci., vol. 48, no. 2, pp. 135-149, 2016.

[5] H. Pratomo, "Pembuatan dan Karakterisasi Membran Komposit Polisulfon Selulosa Asetat untuk Proses Ultrafiltrasi," Pendidik. Mat. dan Sains, vol. 3, no. 8, pp. 168-173, 2019.

[6] A. S. MICHAELS, "SYNTHETIC POLYMERIC MEMBRANES: PRACTICAL APPLICATIONSPAST, PRESENT AND FUTURE," H. B. T.-M. C. Eisenberg, Ed. Pergamon, 1977, pp. 193-204.

[7] M. Vourch, B. Balannec, B. Chaufer, and G. Dorange, "Treatment of dairy industry wastewater by reverse osmosis for water reuse," Desalination, vol. 219, no. 1-3, pp. 190-202, 2008. 